\title{
PELVIC FLOOR MUSCLE EXERCISE IMPROVING SEXUAL SELF-EFFICACY
}

\author{
Nolla Lisa Lolowang ${ }^{1}$, Yati Afiyanti ${ }^{2}$, Titin Ungsianik ${ }^{3}$ \\ ${ }^{1}$ Bethesda Nursing Academy Tomohon, Tomohon, Indonesia \\ ${ }^{2,3}$ Faculty of Nursing Universitas, Depok, Indonesia \\ Corresponding email: lisanolla@yahoo.com
}

\begin{abstract}
Sexuality is one of the most important components of a person's quality of life. Postpartum is the period when women experienced problems in their sexual lives. This study aimed to prove the effects of pelvic floor muscle (PFM) exercise on sexual self-efficacy among primiparous women. This research was a quasi-experiment study with one group time series design, with the number of respondents 32 people. The results showed that the intervention of pelvic floor muscle exercise which performed for six weeks proved to increase the sexual selfefficacy of primiparous mother significantly ( $p=0,001$; CI 95\% 10,53-14,18). PFM exercise is the best way to increase pelvic floor muscle strength that positively affects the enhancement of sexual self-efficacy of primiparous women. It is recommended that PFM exercise become a nursing intervention that should be explained and taught by nurses as a form of postpartum care education.
\end{abstract}

Keywords: PFM exercise, sexual self-efficacy.

\section{INTRODUCTION}

Women's health is a basic right of every woman in her life. Sexuality is one of the important components of quality of life. Sexual function is a very complex issue because it is influenced by the psychosocial situation (Iravani, Janghorbani, Zarean, and Bahrami, 2015). Changes of sexual health in the postpartum period occur as a form of adaptation to the new role as parents (O'Malley, Higgins, \& Smith, 2015). Women usually have sexual problems in their postpartum period. Loss of desire and dyspareunia regarded as the dominant sexual problems. Type of labor played a role in women's sexual life in the postpartum period (Nezhad \& Goodarzi, 2011).

Vaginal delivery is very risky than sectio caesarea delivery, because it can involve pelvic injury or trauma that can influence sexual dysfunction (Barbara et al., 2016). Pelvic injury causes difficulties in the control of elimination and sexual dysfunction. Pelvic floor dysfunction occurs in 38$75 \%$ of women and $10-20 \%$ show clinical symptoms. Symptoms that may occur include lower abdominal pain, urinary incontinence, urgency, polyuria, sexual disorders and dysfunction (Stadnicka, Łepecka-Clusek\&Pilewska-Kozak, 2016). PFM are parts of the pelvis that bulged up to five times of their size at the time of the birth of the fetal head (Bo, 2012). Vaginal delivery involves pressure on the base of the vagina that affects the strength and endurance of the PFM that lead to the decrease of sexual function, especially arousal and orgasm function (Tennfjord, Hilde, and Stær-jensen, 2015). PFM plays an important role in sexual arousal, sexual response and sexual satisfaction of women. PFM dysfunction is one of the major risk factors that cause sexual dysfunction in women. Weak of PFM strength will cause a loss of orgasm and sexual arousal function (Lúcio, Ancona, Lopes, Perissinotto, and Damasceno, 2014). PFM exercise is designed to strengthen the PFM that can prevent 
problems related to sexuality (Topuz \& Seviğ, 2016). PFM exercise is easy, free, non-invasive, effective and practicable everywhere. PFM exercise is recommended to be conducted during the period of pregnancy and postpartum (Bo, 2012; Pal, 2014). PFM exercise can improve sexual functions; desire, arousal and orgasm (Sacomori \& Cardoso, 2015). PFM exercise involves repetitive contractions of the PFM thus increases the strength of the PFM tone and enhance support to the perineum. The increase of the strength and tone of the PFM will permanently restore normal reflex activities as well as the existing control mechanisms (Tosun et al., 2015). Thus the PFM exercise has positive effects on the sexual life of a woman (Kao, Hayter, Hinchliff, Tsai, \& Hsu, 2015).

Sexual self-efficacy plays an important role in the interventions for sexual problems. Sexual self-efficacy is closely related to sexual-concept, as multidimensional construction based on perception of negative and positive feelings of the individual against himself as a sexual being (Rostosky, Dekhtyar, Cupp, \& Anderman, 2008). Research in Nigeria showed that sexual selfefficacy has a significant relationship with postpartum exercise. Sexual self-efficacy increases the awareness of women to do exercise in improving health on the postpartum period. PFM exercise during the postpartum period is closely related to high sexual self-efficacy. Strategies to improve sexual self-efficacy in women during postpartum are very necessary (Adeniyi, Ogwumike, \& Bamikefa, 2013). Components of sexual self-efficacy are desire, sensuality, arousal, orgasm, affection, communication, acceptance, refusing sex (Golmakani, Zare, Khadem, Shareh \& Shakeri, 2015).

Although several studies have shown improvements in sexual dysfunction in postpartum women by doing PFM exercises, however, studies that lead to the effect of PFM exercise on the sexual self-efficacy of primiparous mothers still limited. Researcher needs to consider influencing variables such as interpersonal, contextual, psychological and biological factors (Ferreira et al., 2015). Special design is needed to examine the effect of PFM exercises on improving sexual self-efficacy of primiparous women. That was the reason why researchers wanted to examine the effect of PFM exercises by conducting this research. The purpose of this study was to prove the effects of PFM exercise on sexual self-efficacy in primiparous women.

\section{METHODS}

This study was a quasi-experimental research with one group time series design. PFM exercise intervention was given to primiparous who have passed through 4 weeks after delivery. After signing the informed consent, respondents received the explanation about PFM exercise by the researcher. The population was all the primiparous who were having birth in March 2017 in one of the hospitals in North Sulawesi. A consecutive sampling involved of 32 primiparous women. The formula of comparison of mean in numeric scale more than two measurements was used. The inclusion criteria 
were the willingness to be a respondent, the ability to read and write, having passed through four weeks after delivery, and staying home with her husband. Research ethics approval had been conducted by the ethics committee of the faculty of nursing, Universitas Indonesia. Data were analyzed using a computer program. A univariate analysis was presented in the form of numerical and categorical variables. The bivariate analysis was done using Repeated ANOVA test.

The subjects were asked to lift her PFM and vagina upward, and then hold for 5-10 seconds. After ten seconds, it must be released for ten seconds. The subjects were asked to repeat the motion as many as 20 times in one session. They were asked to do two sessions a day; so, in a day, subject spends time around 15 minutes to perform PFM exercise during three days in a week. The subjects were asked to practice PFM exercise in front of the researcher twice. Researcher followed up the implementation of PFM exercise by phone.

\section{RESULTS}

Table 1. Primiparous Women's Characteristics According to Maternal Age, Partner Age, Length of Marriage, BMI and Infant Weight at Birth $(\mathrm{n}=32)$

\begin{tabular}{lccccc}
\hline \multicolumn{1}{c}{ Variabel } & Median & Minimal & Maximum & $\begin{array}{c}\text { Mean } \\
\text { (SD) }\end{array}$ & CI 95\% \\
\hline Maternal age & 20,5 & 17 & 33 & & \\
Partner age & 23,5 & 20 & 37 & & \\
Length of marriage & 6,5 & 3 & 16 & & \\
BMI & 24,78 & 17,94 & 30,22 & & 370,89 \\
Infant weight at birth & $3.079,69$ & $2.945 .97-3213,41$ & & \\
& & & & &
\end{tabular}

It can be seen that the value of women's age median was 20.5, the median of the husband's age was 23.5 , the median of length of marriage was 6.5 , the median of body mass index was 24.78. Mean of infant weight at birth was 3079.69 grams with a $95 \%$ confidence index from 2945.97 to 3213.41 grams. 
Table 2. Characteristic of primiparous women according to perineal trauma and first time having sexual intercourse after delivery $(n=32)$

\begin{tabular}{lcc}
\hline \multicolumn{1}{c}{ Variable } & Frequency & \% \\
\hline Perineal trauma & 21 & 65,6 \\
$\quad$ Rupture & 11 & 34,4 \\
$\quad$ Episiotomy & 0 & 0 \\
$\quad$ Intact & & \\
First time having sexual intercourse & & \\
after delivery & 4 & 12,5 \\
$\quad$ < weeks & 28 & 87,5 \\
\hline 6 weeks &
\end{tabular}

It can be seen that the majority of primiparous women have perineal rupture, about 21 people (65.6\%). This amount is more than the number of mothers who do an episiotomy, about 11 people (34.4\%). No primiparous had an intact perineum after childbirth. The majority of primiparous women had their first sexual intercourse at more than 6 weeks after delivery, about 28 people $(87.5 \%)$. Women who had sexual intercourse at less than 6 weeks after delivery were 4 people (12.5\%).

Table 3. The overview of Pelvic floor muscle exercise by Primiparous women at home $(\mathrm{n}=32)$

\begin{tabular}{lcccc}
\hline \multicolumn{1}{c}{ Pelvic floor muscle } & \multicolumn{2}{c}{ Session I } & \multicolumn{2}{c}{ Session II } \\
\cline { 2 - 5 } exercise & Frequency & \% & Frequency & \% \\
\hline $\begin{array}{l}\text { Number of contractions } \\
<20 \text { times }\end{array}$ & & & & \\
$\quad$ 20 times & 576 & 100 & 576 & 100 \\
$\begin{array}{l}\text { Duration of } \\
\text { contractions }\end{array}$ & & & & \\
$5-6$ second & 193 & 33,51 & 210 & 36,46 \\
$7-8$ second & 217 & 37,67 & 196 & 34,03 \\
$9-10$ second & 166 & 28,82 & 170 & 29,51 \\
\hline
\end{tabular}

It can be seen that all of the primiparous do PFM exercise with the number of contractions 20 times per session $(100 \%)$. In the first session, the majority of primiparous did one contraction for 7-8 seconds $(37.67 \%)$. In the second session, the majority of primiparous did one contraction for 5-6 seconds $(36.46 \%)$.

Table 4. Effect of Pelvic floor muscle exercise on Sexual Self-efficacy Improvement in Primiparous Women $(\mathrm{n}=32)$

\begin{tabular}{lcc}
\hline \multicolumn{1}{c}{ Sexual self-efficacy } & Mean \pm CI 95\% & p value \\
\hline T0 vs T1 & $6.11 \pm(4,81-7,49)$ & \\
T0 vs T2 & $12,34 \pm(10,53-14,18)$ & $0,001^{*}$ \\
T1 vs T2 & $6,23 \pm(4,42-8,03)$ & \\
\hline * Repeated ANOVA with post hoc Bonferroni &
\end{tabular}


Nolla Lisa Lolowang : Pelvic Floor Muscle Exercise Improving Sexual Self-Efficacy

Table 4 showed that the increase of mean before and after six weeks of doing PFM exercise was 12.34 with the $95 \%$ confidence index from 10.53 to 14.18 . In the post hoc Bonferroni was obtained differences among all groups, with significant values for each ratio was 0,001 .

Table 5. Effect of Pelvic floor muscle exercise on Sexual Self-efficacy Components Improvements among Primiparous Women $(n=32)$

\begin{tabular}{lcccc}
\hline \multirow{2}{*}{$\begin{array}{c}\text { Sexual self- } \\
\text { efficacy } \\
\text { Component }\end{array}$} & T0 vs T1 & T0 vs T2 & T1 vs T2 & value \\
\cline { 2 - 4 } & 13,97 & 20,44 & 6,47 & 0,001 \\
\hline Desire & 11,34 & 20,05 & 8.70 & 0,005 \\
Sensuality & 6,29 & 12.38 & 6,08 & 0,012 \\
Arousal & 10,94 & 16,57 & 5,64 & 0,019 \\
Orgasm & 10,16 & 18,59 & 8,44 & 0,001 \\
Affection & 9,90 & 19,73 & 9,83 & 0,001 \\
Communication & 13,59 & 23,90 & 10,31 & 0,001 \\
Acceptance & 8,90 & 16,71 & 7,81 & 0,002 \\
Refusing Sex & \multicolumn{4}{c}{} \\
\hline
\end{tabular}

It can be seen that the mean value before and after the PFM exercise in all components of sexual selfefficacy increased significantly; Desire $\mathrm{p}=0.001$, sensuality, $\mathrm{p}=0.005$ arousal $\mathrm{p}=0.012$; $\operatorname{\text {orgasm}} \mathrm{p}=$ 0.019 , affection, $\mathrm{p}=0.001$ communication $\mathrm{p}=0.001$, acceptance, $\mathrm{p}=0.001$ refusing sex $\mathrm{p}=0.002$. The component that had increased the most was acceptance, with the mean difference before and after 23.90. The component which had a slight increase was arousal with a mean difference before and after 12.38 .

\section{DISCUSSION}

The results showed that the component of sexual self-efficacy increased significantly after 6 weeks doing PFM exercise. In this study, sexual self-efficacy in primiparous women increased significantly after doing PFM exercise. This is supported by the results of self-report of the implementation of PFM exercise at home which showed that all primiparous women did PFM exercise regularly for six weeks with regard to the number of contraction of 20 contractions of each session, as well as duration of contraction varies from 5-10 seconds.

The self-efficacy component that has the least increase was the physical component. Arousal and orgasm were two of the physical component that increased slightly. For Indonesian people, physical aspect was a very difficult component to be expressed to others. In contrast, the studies conducted in western allowed the researchers to record changes in the reproductive organs during a sexual response (Puppo, 2013). PFM exercise could improve sexual self-efficacy as a construct that 
can make a valuable contribution to the approaches to understanding sexual response and sexual problems in women (Rowland et al., 2015).

The arousal component is associated with sexual satisfaction and sexual stimulation prior to sexual intercourse. The research of Cappell et al (2016) showed that the postpartum women masturbated to obtain sexual satisfaction after the first week of postpartum. Some mothers' desire for sexual intercourse could re-emerge in a week - the early weeks postpartum, but health workers advise mothers to have sexual intercourse with a partner in the six weeks after delivery.

Orgasm also increased slightly compared to the other components. This component is related to the ability to respond sexually, vaginal lubrication, the comfort of sexual intercourse without pain, as well as the ability to reach the peak of orgasm. The results of Herbenick, Mullinax, and Mark (2014) study showed that the decrease in the quality of these relationships affect the decrease in sexual desire, satisfaction and intimacy as a whole. The problem that occurs is when a couple in intimate relationships wants a different frequency of sexual activity. When mothers have low sexual desire, the ability to achieve orgasm will be disrupted. When a mother is having problems with the ability to orgasm then it will tend to be non-assertive and negative attitude towards sexual activity (McCabe et al., 2010).

These results are consistent with the research of El-begway, Elshamy, and Hanfy (2010) which showed an increase in sexual function after doing PFM exercise. Sexual function that increases, including desire, arousal, and orgasm. Orgasm experienced a small increase caused by perineal trauma experienced by mothers after childbirth. In addition to perineal trauma, which occurs due to factors hypoestrogenic lactation process also resulted in decreased sexual function. The results of this study are also consistent with the study of Mansour, Shebl, and Waheda (2014) which showed that the majority of mothers experience dyspareunia caused by episiotomy at delivery (66.4\%).

Research of Shirvani et al (2010), about maternal sexuality after childbirth showed similar results. Research results showed that there was a statistically significant improvement in sexual function; arousal, desire, lubrication between the first measurement and the fourth measurement. Oakley et al (2016) in his research showed that PFM exercise after childbirth improved women's quality of life and sexual function. Sexual function that increased after PFM exercise was arousal and orgasm. Similar results were shown by Lurie et al (2013) that sexual function improved after 24 weeks postpartum.

The research result Golmakani et al (2015) on sexual self-efficacy in primiparous mother after PFM exercise, showed that after PFM exercises for 8 weeks component of sexual self-efficacy increased; desire, sensuality, arousal, orgasm, affection, communication, acceptance, and refusing sex. The physical factor has increased slightly because since the postpartum period women usually experience weakness, anxiety with physical changes that occur after childbirth and busy in taking care 
of her baby. Research Mohktar et al (2013) suggesting that Pelvic floor muscle exercise improve sexual function. Nazarpour, Simbar, Tehrani, and Majd (2017) in his research show that PFM exercise are given for 12 weeks increases the physiological components of sexual self-efficacy; desire, arousal, and orgasm. Improvement of sexual function caused by an increase in the strength of the PFM, which consequently affects the anatomical position of the erectile tissue of the clitoris, which is directly related to sexual stimulation. Sexual response in women is generated by a mechanism of feedback between the hormones secreted from the ovaries to the hypothalamus and anterior pituitary gland to produce sex cells and sex steroid hormones. Sexual stimulation results in vasocongestion veins cause distension genitals vaginal lubrication. Passion or arousal is characterized by myotonia which produces rhythmic contractions volume and accidental (Lowdermilk, Perry, \& Cashion, 2014). The corpus spongiosum of the urethra experienced vasocongestion thus increasing sexual desire (Puppo, 2013).

In this study, the component of sexual self-efficacy that experienced the greatest improvement was acceptance. Acceptance component is related to the mother's acceptance of her post-partum state and her comfort in having sexual intercourse with her partner. For women, body image is closely related to sexual satisfaction. When a woman has to feel welcome and have a good self-image of his body, indirectly sexual satisfaction would be an increase. Research of Træen, Markovic, and Kvalem (2016) showed that a woman's sexual satisfaction starts from the phase in which he accepted and felt the emotional closeness with their partner to have a commitment in a relationship together.

Research of Norton, Smith, Magriples, and Kershaw (2016) showed similar results. Component that increased was communication as a psychological component. Good communication between spouses can improve sexual self-efficacy because of readiness initiate sexual intercourse after childbirth or sexual self-efficacy is determined not only by the mother but also her partner. Sexual satisfaction is very important to be maintained in improving the quality of a woman's life, not only for himself but also in conjunction with a partner (Khajehei, Doherty, Tilley, and Sauer, 2015). Sexual satisfaction depends on the desire to have sex that comes from personal desire and consent spouse (Sanchez, Moss-Racusin, Phelan, \&Crocker, 2011). Maturity think of husband would affect the sexual life, because postpartum ability of a woman to have sexual relations is very different to the previous state (Ferreira, Narciso, Novo, and Pereira, 2014).

Sexual self-efficacy is closely related to the quality of marriage, whether of relationships, intimacy, and emotional satisfaction (Nooripour \& Apsche, 2014). Research of Nezhad and Goodarzi (2011) showed that sexual satisfaction in the marital relationship is affected by the length of the intimate relationship undertaken by married couples. Affection plays the most important role in the quality of the relationship. When psychological factors are met then, the physiological factors will follow and then it can increase satisfaction and happiness in the family (Azarian, Ghorbanshirodi, and Khalatbari, 2014). That is why sexual self-efficacy was associated with a positive attitude among 
couples (Hasankhani, 2016). Intervention of PFM exercise is a form of health promotion that should be taught by health personnel especially nurses as a form of education in postpartum care package.

\section{CONCLUSION}

PFM exercise that performed for six weeks proved improve sexual self-efficacy primiparous mother, significantly. There are significant differences between sexual self-efficacy before and after doing PFM exercise. Active approach of the nurse as a provider of nursing care is needed to overcome sexual problems faced by women, especially mothers postpartum. Consultation to explore problems facing needs to be improved so that it can help overcome sexual related problems.

\section{REFERENCE}

Azarian, M., Ghorbanshirodi, S., \& Khalatbari, J. (2014). Relation between Sexual Self-Efficacy , Sensation-Seeking and Marital Satisfaction in Married Woman in Islamic Azad University of. Journal of Social Issues \& Humanities, 2(7), 209-212.

Barbara, G., Pifarotti, P., Facchin, F., Cortinovis, I., Dridi, D., Ronchetti, C., ... Vercellini, P. (2016). Impact of Mode of Delivery on Female Postpartum Sexual Functioning: Spontaneous Vaginal Delivery and Operative Vaginal Delivery vs Cesarean Section. The Journal of Sexual Medicine, 13(3), 393-401. http://doi.org/10.1016/j.jsxm.2016.01.004

Bo, K. (2012). Pelvic floor muscle training in treatment of female stress urinary incontinence, pelvic organ prolapse and sexual dysfunction. World Journal of Urology, 30(4), 437-443. http://doi.org/10.1007/s00345-011-0779-8

Cappell, J., MacDonald, T. K., \& Pukall, C. F. (2016). For new mothers, the relationship matters: Relationship characteristics and postpartum sexuality. The Canadian Journal of Human Sexuality, 25(2), 126-137. http://doi.org/10.3138/cjhs.252-A5

El-begway, A. F., Elshamy, F. F., \& Hanfy, H. M. (2010). The Effect of Pelvic Floor Exercise on Sexual Function after Vaginal Delivery. Medical Journal of Cairo University, 78(2), 27-31.

Ferreira, L. C., Narciso, I., Novo, R. F., \& Pereira, C. R. (2014). Predicting couple satisfaction : the role of differentiation of self, sexual desire and intimacy in heterosexual individuals. Sexual and Relationship Therapy, 29(4), 390-405. http://doi.org/http://dx.doi.org/10.1080/14681994.2014.957498

Golmakani, N., Zare, Z., Khadem, N., Shareh, H., \& Shakeri, Mohammad, T. (2015). The effect of pelvic floor muscle exercises program on sexual selfefficacy in primiparous women after delivery. Iranian Journal of Obstetrics, Gynecology and Infertility, 17(103), 21-32. Retrieved from http://ijogi.mums.ac.ir/pdf_3007_bf27aec9cc618ade4c272ae1bec601ac.html\%5Cnhttp://ovidsp. ovid.com/ovidweb.cgi?T=JS\&PAGE=reference $\& D=$ =med12\&NEWS=N\&AN=2014580714 
Nolla Lisa Lolowang : Pelvic Floor Muscle Exercise Improving Sexual Self-Efficacy

Hasankhani, S. (2016). The Effectiveness of PREPARE-ENRICH Program on Subjective Well-Being and Sexual Self-Efficacy of Iranian Couples. International Journal of Humanities and Cultural Studies, 3(1), 1839-1847.

Herbenick, D., Mullinax, M., \& Mark, K. (2014). Sexual Desire Discrepancy as a Feature , Not a Bug , of Long-Term Relationships : Women's Self-Reported Strategies for Modulating. Journal of Sexual Medicine, 2196-2206. http://doi.org/10.1111/jsm.12625

Iravani, M., Janghorbani, M., Zarean, E., \& Bahrami, M. (2015). An overview of systematic reviews of normal labor and delivery management. Iranian Journal of Nursing and Midwifery Research, 20(3), 293-303. Retrieved from

http://www.pubmedcentral.nih.gov/articlerender.fcgi?artid=4462052\&tool=pmcentrez\&renderty pe $=$ abstract

Kao, H.-T., Hayter, M., Hinchliff, S., Tsai, C.-H., \& Hsu, M.-T. (2015). Experience of pelvic floor muscle exercises among women in Taiwan: a qualitative study of improvement in urinary incontinence and sexuality. Journal of Clinical Nursing, 24(13-14), 1985-94. http://doi.org/10.1111/jocn.12783

Khajehei, M., Doherty, M., Tilley, P. J. M., \& Sauer, K. (2015). Prevalence and Risk Factors of Sexual Dysfunction in Postpartum. The Journal of Sexual Medicine, 12(6), 1415-1426. http://doi.org/10.1111/jsm.12901

Lúcio, A. C., Ancona, C. A. L. D., Lopes, M., Perissinotto, M. C., \& Damasceno, B. P. (2014). The effect of pelvic floor muscle training alone or in combination with electrostimulation in the treatment of sexual dysfunction in women with multiple sclerosis, 1761-1769. http://doi.org/10.1177/1352458514531520

Lurie, S., Aizenberg, M., Sulema, V., Boaz, M., Kovo, M., \& Golan, A. (2013). Sexual function after childbirth by the mode of delivery : a prospective study. Archives of Gynecology and Obstetrics. http://doi.org/10.1007/s00404-013-2846-4

Mansour, S., Shebl, A., \& Waheda, S. (2014). The Effect of Sexual Counseling Program on Pain Level and Sexual Function among Women with Dyspareunia. Journal of Education and Practice, 5(3), 208-220.

Mccabe, M., Althof, S. E., Assalian, P., Chevret-measson, M., Leiblum, S. R., \& Wylie, K. (2010). Psychological and Interpersonal Dimensions of Sexual Function and Dysfunction. Journal of Sexual Medicine, 7, 327-336. http://doi.org/10.1111/j.1743-6109.2009.01618.x

Mohktar, M. S., Ibrahim, F., Rozi, N. F., Yusof, J., Ahmad, S. A., Yen, K. S., \& Omar, S. Z. (2013). A quantitative approach to measure women's sexual function using electromyography: A preliminary study of the Kegel exercise. Medical Science Monitor, 19, 1159-1166. http://doi.org/10.12659/MSM.889628

Nazarpour, S., Simbar, M., Tehrani, F. R., \& Majd, H. A. (2017). Effects of Sex Education and Kegel Exercises on the Sexual Function of Postmenopausal Women : A Randomized Clinical Trial. The Journal of Sexual Medicine, 1-9. http://doi.org/10.1016/j.jsxm.2017.05.006

Nezhad, M. Z., \& Goodarzi, A. M. (2011). Sexuality, Intimacy, and Marital Satisfaction in Iranian First-Time Parents. Journal of Sex \& Marital Therapy, 37(2), 77-88. http://doi.org/10.1080/0092623X.2011.547336 
Nooripour, R., \& Apsche, J. (2014). Effectiveness of self-efficacy group therapy on problem solving skill and sexual self-efficacy in addicted women. ... JourNAl of BehAviorAl ..., 9(1), 35-39. Retrieved from http://www.baojournal.com/IJBCT/IJBCT-9_1/A05.pdf

Norton, M. K., Smith, M. V., Magriples, U., \& Kershaw, T. S. (2016). Masculine Ideology, Sexual Communication, and Sexual Self-Efficacy Among Parenting Adolescent Couples. American Journal of Community Psychology, 27-35. http://doi.org/10.1002/ajcp.12078

Oakley, S. H., Ghodsi, V. C., Crisp, C. C., Estanol, M. V., Westermann, L. B., Novicki, K. M., ... Pauls, R. N. (2016). Impact of Pelvic Floor Physical Therapy on Quality of Life and Function After Obstetric Anal Sphincter Injury: A Randomized Controlled Trial. Female Pelvic Medical Reconstruction Surgeon, 22(4), 205-213. http://doi.org/10.1097/SPV

O'Malley, D., Higgins, A., \& Smith, V. (2015). Postpartum sexual health: A principle-based concept analysis. Journal of Advanced Nursing, 71(10), 2247-2257. http://doi.org/10.1111/jan.12692

Pal, M. (2014). O R I G I N A L A RTICL E Pelvic floor exercises - A clinical study. Asian Journal Of Medical Sciences, 5(3). Retrieved from http://nepjol.info/index.php/AJMS

Puppo, V. (2013). Anatomy and Physiology of the Clitoris , Vestibular Bulbs , and Labia Minora With a Review of the Female Orgasm and the Prevention of Female Sexual Dysfunction. Clinical Anatomy, 152(July 2012), 134-152. http://doi.org/10.1002/ca.22177

Rostosky, S. S., Dekhtyar, O., Cupp, P. K., \& Anderman, E. M. (2008). Sexual self-concept and sexual self-efficacy in adolescents: a possible clue to promoting sexual health? Journal of Sex Research, 45(3), 277-286. http://doi.org/10.1080/00224490802204480

Rowland, D. L., Adamski, B. a, Neal, C. J., Myers, A. L., \& Burnett, A. L. (2015). Self-efficacy as a relevant construct in understanding sexual response and dysfunction. Journal of Sex \& Marital Therapy, 41(1), 60-71. http://doi.org/10.1080/0092623X.2013.811453

Sacomori, C., \& Cardoso, F. L. (2015). Predictors of improvement in sexual function of women with urinary incontinence after treatment with pelvic floor exercises: a secondary analysis. The Journal of Sexual Medicine, 12(3), 746-755. http://doi.org/10.1111/jsm.12814

Sanchez, D., Moss-Racusin, C., Phelan, J. E., \& Crocker, J. (2011). Relationship Contingency and Sexual Motivation in Women : Implications for Sexual Satisfaction. Archives of Sexual Behavior, 40, 99-110. http://doi.org/10.1007/s10508-009-9593-4

Shirvani, M. ., Nesami, M. ., \& Bavand, M. (2010). Maternal Sexuality after Child Birth among Iranian Women. Pakistan Journal of Biological Sciences.

Stadnicka, G., Łepecka-Klusek, C., \& Pilewska-Kozak, A, B. (2016). Pelvic floor muscle disorders and women's quality of life 1 . Department of the Basics of Midwifery, Faculty of Health Sciences , Medical University of. Programme Health Scienses, 6(1), 95-101.

Tennfjord, M. K., Hilde, G., \& Stær-jensen, J. (2015). Coital Incontinence and Vaginal Symptoms and the Relationship to Pelvic Floor Muscle Function in Primiparous Women at 12 Months Postpartum : A Cross-Sectional Study. Journal Sexual Medicine, 12, 994-1003. http://doi.org/10.1111/jsm.12836

Topuz, Ş., \& Seviğ, E. Ü. (2016). Effects of kegel exercises applied to urinary incontinence on sexual satisfaction. 
Nolla Lisa Lolowang : Pelvic Floor Muscle Exercise Improving Sexual Self-Efficacy

Træen, B., Markovic, A., \& Kvalem, I. L. (2016). Sexual satisfaction and body image : a crosssectional study among Norwegian young adults. Sexual and Relationship Therapy, (1), 1-15. http://doi.org/10.1080/14681994.2015.1131815

Willans, A. (2014). The role of pelvic floor muscle exercise in the treatment of female sexual dysfunction. Journal of the Association of Chartered Physiotherapists in Women's Health, (115), 22-29. 